\title{
ECONOMIA COMPARTILHADA E TRABALHO UBERIZADO: AS TRANSFORMAÇÕES NAS RELAÇÕES DE TRABALHO A PARTIR DOS APLICATIVOS
}

\section{Giulia Signor * Carina Lopes de Souza **}

\begin{abstract}
RESUMO: A presente pesquisa tem como tema o trabalho uberizado, responsável por modificar a dinâmica de trabalho e a relação de emprego. Busca-se responder o seguinte questionamento: quais as transformações nas relações de trabalho decorrentes da Economia do Compartilhamento e do trabalho uberizado? A pesquisa tem como objetivos: a) estudar o que é a Economia do Compartilhamento e o trabalho uberizado; b) analisar como se desenvolve o trabalho em aplicativos; c) estudar qual o posicionamento do Tribunal Superior do Trabalho acerca do trabalho uberizado e as propostas legislativas. Utilizar-se-á o método de abordagem dedutivo e a técnica de pesquisa documental.
\end{abstract}

PALAVRAS-CHAVE: Economia do Compartilhamento; Uberização; Trabalho; Prestação de Serviço; Vínculo Empregatício.

\section{SHARING ECONOMY AND UBERIZED WORK: THE TRANSFORMATIONS IN LABOR RELATIONS BY APP}

\begin{abstract}
This research has as theme the uberization work, responsible for modifying the dynamic work and the employment relationship. It seeks to answer the following question: what are the transformations in work relations resulting from the Economy of Sharing and uberized work? The research aims to: a) study what the Sharing Economy is and uberized work; b) to analyze how the work in applications is developed; c) to study the position of the Superior Labor Court regarding uberized work and legislative proposals. The deductive approach method and the documentary research technique will be used.
\end{abstract}

KEY-WORDS: Sharing Economy; Uberization; Labor; Provision of Service; Employment Bond.

\footnotetext{
* Graduada em Direito pela Faculdade Meridional - IMED. Mestranda em Direito pela Faculdade Meridional IMED, em sua área de concentração em Direito, Democracia e Sustentabilidade, linha de pesquisa em Efetividade do Direito, da Democracia e da Sustentabilidade. Beneficiária da taxa PROSUP/CAPES. Advogada Membro dos grupos de pesquisa Latin America Privacy Hub e Direito, Novas Tecnologias e Desenvolvimento, da Faculdade Meridional - IMED. Currículo Lattes: http://lattes.cnpq.br/6380850649791969. E-mail: giulia.signor@yahoo.com.br. Orcid: http://orcid.org/00000002-4987-1443.

** Graduada em Direito pela Faculdade Meridional - IMED. Mestranda em Direito pela Faculdade Meridional IMED, em sua área de concentração em Direito, Democracia e Sustentabilidade, linha de pesquisa em Efetividade do Direito, da Democracia e da Sustentabilidade. Advogada. Membro do Grupo de Estudos e Pesquisas em Direitos Fundamentais, Democracia e Desigualdade da Faculdade Meridional- IMED vinculado ao CNPq. Currículo Lattes: http://lattes.cnpq.br/3105828369221271. E-mail: adv.carinalopes@gmail.com. Orcid: http://orcid.org/0000-0002-8770-3790.
} 


\section{INTRODUÇÃO}

Com mais de um milhão de motoristas ${ }^{1}$ cadastrados no Brasil, a Uber tem se mostrado como uma alternativa a complementação e a geração de renda diante do desemprego e da instabilidade financeira. Este aplicativo de transporte, dentre tantos outros, faz parte de um sistema que surgiu para reescrever a lógica do trabalho no século XXI: a Economia do Compartilhamento.

Esse novo modelo econômico utiliza das tecnologias da informação e comunicação, como smartphones, aplicativos, websites, para intermediação de prestações de serviços. Apresentou um crescimento vertiginoso a partir da crise de 2009 e com a popularização de seu maior representante, a Uber, em 2014, fez com que a Economia do Compartilhamento deixasse de ser apenas uma alternativa e passasse a constituir a principal fonte de renda de muitos trabalhadores.

Diante disso, o que antes era apenas um passatempo ou uma ocupação secundária, agora é um trabalho de dedicação exclusiva de muitos cadastrados, o que acarreta numa modificação das dinâmicas de trabalho até então conhecidas, uma vez que toda a organização é realizada por meio de aplicativos e algoritmos.

Assim, levanta-se o seguinte problema: quais as transformações nas relações de trabalho decorrentes da Economia do Compartilhamento e do trabalho uberizado?

Para responder o questionamento, será estudado, no primeiro tópico o que é a Economia do Compartilhamento e o trabalho uberizado. No segundo tópico analisar-se-á como se desenvolve o trabalho em aplicativo e suas principais características e modificações nas dinâmicas de trabalho, tendo como parâmetro o aplicativo Uber. Por fim, no terceiro e último tópico, será estudado o posicionamento do Judiciário brasileiro acerca do trabalho uberizado, bem como as propostas legislativas para a sua regulamentação.

Para tanto foi utilizado como método de abordagem o dedutivo, como método de procedimento o monográfico e como técnica de pesquisa a pesquisa bibliográfica e documental.

\section{ECONOMIA DO COMPARTILHAMENTO E TRABALHO UBERIZADO}

\footnotetext{
${ }^{1}$ Dados retirados do site oficial do aplicativo (UBER, 2020d)
} 
As tecnologias da informação e comunicação, cada vez mais, fazem parte das atividades cotidianas da população global. Tarefas, antes alheias a qualquer inovação tecnológica, passam a ser modernizadas por meio de aplicativos de smartphones e websites, tais como compartilhamento de objetos, intermediação de prestações de serviços e até mesmo aluguel de imóveis subutilizados. Diante disso, constitui-se aquilo que chamamos de Economia do Compartilhamento.

Primeiramente, antes mesmo de chegar a uma descrição sólida do que compõe essa nova economia, há de se referir que o termo é demasiadamente abrangente, o que se mostra como um problema para sua conceituação. A Economia do Compartilhamento engloba desde sistema de utilização de recursos ociosos e serviços (como Airbnb e Uber), como sistema de compartilhamento de bens para produção colaborativa (como a Wikipédia), sendo que o ponto comum entre essas diferentes modalidades é a conexão de sujeitos pela internet e a disseminação de novos modelos de negócios (ZANATTA, 2017, p. 81).

Importante destacar que, embora a Economia do Compartilhamento seja um conceito, relativamente, novo, a ideia de utilização de plataformas para recirculação de bens e serviços não é. Os primeiros sistemas conhecidos de compartilhamento surgiram em 1995, sendo eles o eBay e o Craiglist, focados na recirculação de bens. Após mais de duas décadas do surgimento, o avanço tecnológico possibilitou a inserção de softwares mais aprimorados, os quais reduziram os custos e os riscos das transações (SCHOR, 2017, p.24).

Conforme anteriormente referido, a Economia do Compartilhamento abrange mais de um seguimento de negócios. Diante disso, Schor (2017, p.24) separa a economia compartilhada em quatro categorias amplas: a) recirculação de bens; b) uso expandido de bens duráveis; c) troca de serviços; d) compartilhamento de bens produtivos. A primeira categoria faz referência as plataformas de compra e venda de produtos, em sua maioria seminovos ou usados.

A segunda categoria de plataformas tem como foco o compartilhamento de produtos subutilizados, bem como aluguel de veículos, compartilhamento de caronas, serviços de transporte, aluguel de imóveis ou quartos. Nessa categoria encontram-se os aplicativos mais conhecidos da Economia do Compartilhamento, como por exemplo o aplicativo Uber.

A terceira categoria foca na prestação de serviços, realizando a intermediação de usuários que precisam de tarefas feitas e pessoas com disponibilidade para realizá-las. Esse ramo não atingiu uma popularidade tão grande quanto as duas primeiras categorias. A quarta e última categoria consiste no "compartilhamento de bens ou espaços de modo a possibilitar a 
produção, em vez do consumo" (SCHOR, 2017, p. 26), tendo como exemplo o compartilhamento de escritórios, plataformas de educação, ferramentas de criação compartilhadas.

A partir destes conceitos, tem-se que a Economia do Compartilhamento pode ser diferenciada a partir de três principais fatores: “(i) o recurso compartilhado (material/imaterial ou híbrido); (ii) a finalidade do compartilhamento (consumo/produção) e a (iii) estrutura de controle e gestão da plataforma (corporativa e hierarquizada/cooperativa e horizontal)." (ZANATTA, 2017, p. 103). Nota-se que a estrutura central da Economia do Compartilhamento é a colaboração entre as pessoas, podendo ser tanto corporativa, com fins lucrativos, como a Uber, quanto cooperativa, sem fins lucrativos, como a Wikipédia.

Diante das características acima descritas, a Economia do Compartilhamento, pode ter como um de seus conceitos - diante da amplitude de significados - "uma onda de novos negócios que usam a internet para conectar consumidores com provedores de serviço para trocas no mundo físico." (SLEE, 2017, p.21). Esse conceito desenvolvido por Slee é utilizado, principalmente, para caracterizar a vertente da Economia do Compartilhamento voltada para o corporativismo e a obtenção de lucros, onde estão inseridos os aplicativos de prestação de serviço de transporte, os quais serão o objeto desta pesquisa.

A ascensão das plataformas de economia compartilhada ocorreu após a crise de 2008-2009, apresentando-se como uma alternativa diante da recessão econômica, desemprego e instabilidade do sistema financeiro (ZANATTA, 2017, p. 88). O que antes surgia como uma proposta de consumo consciente, utilização de bens ociosos e troca de serviços, passa a se tornar interesse do sistema financeiro, principalmente dos investidores do Vale do Silício, e da mídia (ZANATTA, 2017, p. 90).

A Uber mostra-se como um exemplo de crescimento a partir de aportes de capitais de risco, de empresas como Google Ventures, Goldman Sachs, do investidor Jeff Bezos, entre diversos outros. A empresa que começou como uma startup de serviço de carros de luxo em 2009, em São Francisco, na Califórnia, em 2017 já havia sido avaliada em US\$ 11 bilhões (onze bilhões de dólares) (SLEE, 2017, p.101). Segundo Kramer (2017, p. 84)

A evolução aconteceu rapidamente, mas, as coisas complicaram-se quando teve início o que pode-se chamar de "profissionalização" desse modelo de negócio, ou seja, quando a UBER entrou no mercado, passou ser algo mais de que dividir combustível, taxas, pedágios e manutenção, mais do que dividir caronas. 
Esse crescimento e popularização das plataformas de economia compartilhada possibilitou o surgimento de um novo ramo de atividade voltado ao trabalho em aplicativo. A população antes atingida pelo desemprego ou pela informalidade passa a exercer o trabalho em aplicativos como forma de geração e complementação de renda. Em estudo realizado por Rosenblat (2018), constatou-se que a maioria dos motoristas do aplicativo Uber trabalham meio-período para complementação de renda ou trabalham por tempo integral e retiram do aplicativo o seu sustento.

Adotando uma posição mais acrítica, o cenário criado pela Economia do Compartilhamento mostra-se benéfico para quem trabalha, ou nos termos utilizados pelas plataformas, torna-se parceiro. Conforme Antunes e Filgueiras (2020, p. 31): "afirma-se também que as plataformas e aplicativos criam ambientes de trabalho mais atrativos para quem tem estilos diferentes de vida, sem a rigidez dos empregos tradicionais e assim facilitam a manutenção de um emprego".

Contudo, ao partir para uma análise crítica da Economia do Compartilhamento, principalmente sobre os aplicativos de prestação de serviço, tal como o Uber, verifica-se que na realidade, os aplicativos utilizam da mão-de-obra dos trabalhadores, então denominados de parceiros, "sem qualquer garantia de jornada e de remuneração, o que acarreta implicações importantes na dinâmica da gestão e controle da forma de trabalho." (ANTUNES; FILGUEIRAS, 2020, p.32).

Ao mesmo passo que os aplicativos vendem a sua proposta como uma oportunidade de liberdade, flexibilidade e independência aos trabalhadores e sustentam a ideia do autogerenciamento, isto é, do "seja seu próprio chefe", quando se refere as proteções legais, a "Uber os classifica como contratantes independentes, significando que estão amplamente excluídos do emprego e das proteções das leis trabalhistas as quais os empregados tem direito"² (ROSENBLAT, 2018, tradução nossa).

Essa nova modulação das relações de trabalho trazidas pela inserção do aplicativo Uber e similares no mercado possuí tamanho impacto que já gerou um novo termo para descrevê-la: "uberização das relações de trabalho" e um verbo, uberizar (FONTES, 2017, p. 54). Não se trata apenas da utilização da tecnologia para intermediar uma prestação de

\footnotetext{
2 Texto original: “[...] Uber classifies them as independent contractors, meaning they are largely excluded from the employment and labor law protections to which employees are entitled"
} 
serviço, mas sim da criação de um novo modelo de negócios, de escala global, o qual ressignificou diversos conceitos das relações de trabalho.

Com isso, levanta-se o debate acerca da regulamentação das relações entre aplicativos e parceiros cadastrados, bem como sobre a existência ou não de um vínculo empregatício entre as partes. De fato, a legislação trabalhista brasileira não possuí qualquer tipo de previsão acerca dos trabalhos que utilizam, majoritariamente, as tecnologias da informação e comunicação para seu desenvolvimento, o que torna complexo o seu enquadramento nas modalidades já regulamentadas, como trabalho autônomo ou vínculo de emprego formal.

Levando em conta esse cenário, mostra-se necessário analisar, pormenorizadamente, as características do trabalho em plataforma e as mudanças trazidas pela tecnologia nos elementos caracterizadores das relações de trabalho e emprego, a fim de que seja possível verificar quais as possíveis alterações na legislação trabalhista decorrentes desse contexto.

\section{AS MODIFICAÇÕES NAS RELAÇÕES DE TRABALHO DECORRENTES DO TRABALHO UBERIZADO}

O principal debate que permeia as relações de trabalho uberizadas é se essa modalidade de trabalho configura, ou não, uma relação de emprego nos moldes reconhecidos pela Consolidação das Leis do Trabalho (CLT), ou se a tecnologia proporcionada pelas empresas-aplicativos configura somente uma intermediação entre o trabalhador autônomo e possíveis clientes. Nessa perspectiva, é preciso compreender como funciona o trabalho em aplicativos, utilizando-se o exemplo da Uber como parâmetro para o estudo.

Para que o parceiro/trabalhador ingresse nos quadros de cadastrados da Uber é necessário que sejam preenchidos alguns requisitos exigidos pela empresa, tais como: a) possuir carteira nacional de habilitação $(\mathrm{CNH})$ com anotação sobre o exercício de atividade remunerada; b) possuir veículo de acordo com os requisitos da legislação municipal da cidade onde irá atuar, com apresentação do certificado de registro e licenciamento de veículo (CRLV); c) apresentação de relatório de antecedentes criminais (UBER, 2020a).

Após a aprovação para a criação do perfil de motoristas, o aplicativo exige dados bancários para realização de pagamentos, documentos de identidade oficiais, data de 
nascimento, assinatura, foto do motorista, informações sobre o seguro do veículo, informações sobre histórico de direção e direito de trabalhar (UBER, 2020b).

Ainda, é necessária a concordância com os termos de uso do aplicativo, onde autoriza-se a coleta de dados e o repasse de informações pelo aplicativo. Dentre essas informações estão: dados de localização, dados de utilização do aplicativo, dados sobre o aparelho de celular e de comunicação (mensagens de texto e ligações), avaliações recebidas no aplicativo e comentários realizados pelos usuários (UBER, 2020b).

As informações coletadas e armazenadas pelo algoritmo ${ }^{3}$ do aplicativo são utilizadas para avaliação automática do motorista parceiro, bem como para monitoramento de como o motorista dirige, observando freadas, acelerações e a velocidade do veículo (ROSENBLAT, 2018). Esses dados servem para controle do motorista, sendo que ao serem constatadas avaliações e comentários negativos pelo algoritmo do aplicativo ocorre o bloqueio automático da conta do parceiro/trabalhador.

A partir disso é possível notar que o aplicativo não é meramente um intermediador entre o motorista e o cliente final, mas organiza-se da mesma maneira que uma empresa tradicional, com requisitos para cadastro para prestação do serviço, monitoramento das atividades e controle sobre a qualidade do serviço prestado, entretanto, sem a devido reconhecimento do vínculo entre seus motoristas parceiros. Conforme Antunes (2018, s/p):

\begin{abstract}
A Uber é outro exemplo mais que emblemático, trabalhadores e trabalhadores com seus automóveis, isto é, com seus instrumentos de trabalho, arcam com suas despesas de seguridade, com os gastos de manutenção do veículo, de alimentação, limpeza, etc... enquanto o aplicativo, na verdade, uma empresa privada global de assalariamento disfarçado sob a forma de trabalho desregulamentado apropria-se do mais-valor gerado pelo serviço dos motoristas, sem preocupações com deveres trabalhistas historicamente conquistados pela classe trabalhadora.
\end{abstract}

No que se refere a execução do serviço, o motorista deve permanecer online no aplicativo a fim de que seja realizada a conexão com o cliente. No momento em que é confirmada a corrida, o próprio aplicativo define o valor a ser pago, considerando fatores como distância a ser percorrida e o tempo de viagem. Desse valor, uma porcentagem é retida pelo aplicativo como uma espécie de taxa de intermediação. Além disso, o algoritmo possui tarifa dinâmica, o que quer dizer que a Uber estabelece áreas da cidade onde os valores das

\footnotetext{
${ }^{3}$ Para Harari (2016, p. 91), "um algoritmo é um conjunto metódico de passos que pode ser usado na realização de cálculos na resolução de problemas e na tomada de decisões. Não se trata de um cálculo específico, mas do método empregado quando se fazem cálculos."
} 
corridas são mais altas, como uma espécie de condução indireta (FERRAZ; FRANCO, 2019 p. 852).

Outro fator a ser considerado sobre o trabalho em aplicativos é, que apesar do discurso promovido, principalmente pela Uber, de que "você define seu próprio horário" e que o motorista possui liberdade para definir quando quer trabalhar, os próprios termos de uso do aplicativo trazem a possibilidade de desativação estiver com uma taxa de aceitação de corrida menor que a média (ANTUNES; FILGUEIRAS, 2020, p. 34). Ainda, o aplicativo possuí uma política de bônus após um número determinado de corridas (UBER, 2020c), o que faz com que o motorista se force a permanecer online a fim de manter esse aumento nos rendimentos.

Além disso, o motorista ainda é induzido a ofertar agrados para seus clientes, tais como água, guloseimas (balas, chicletes), manter o veículo limpo e preferencialmente com arcondicionado a fim de que, ao final de cada corrida, receba uma nota maior em sua avaliação (FERRAZ; FRANCO. 2018, p. 852).

É possível notar, a partir desses elementos que definem o trabalho em aplicativo, no caso da empresa Uber, que a sistemática adotada para controle e manutenção da qualidade na prestação de serviço são diferentes do que, habitualmente, as empresas adotam. A principal forma de gestão das atividades é por meio de algoritmo, o que, em um primeiro momento, transpassa a ideia de imparcialidade, mas que são programados previamente para direcionar os motoristas aos objetivos definidos pela empresa (FERRAZ; FRANCO, 2018, p. 852).

Diante dessas determinações estabelecidas pelo aplicativo, não se mantém o discurso de que o motorista é "seu próprio chefe". A empresa estipula, unilateralmente, métodos de controle e um padrão de execução do serviço que não condiz com o discurso de autogerenciamento. Se o motorista fosse, de fato, seu próprio chefe, deveria ele estipular seus padrões, seus valores e sua disponibilidade de trabalho, sem correr o risco de sofrer qualquer represália, como desligamentos. Para Abilio (2019, p.2):

Nessa condição de quem adere e não mais é contratado, o trabalhador uberizado encontra-se inteiramente desprovido de garantias, direitos ou segurança associados ao trabalho; arca com riscos e custos de sua atividade; está disponível ao trabalho e é recrutado e remunerado sob novas lógicas. 
Nesse sentido, observa-se que o trabalho executado pelos motoristas parceiros é na realidade, muito similar ao realizado em uma empresa tradicional, com as mesmas exigências de um empregado. Ocorre, entretanto, a modificação, pelo uso da tecnologia, de alguns dos requisitos presentes no vínculo de emprego tradicional ${ }^{4}$, tal como a habitualidade e a subordinação.

A fim de discutir esses dois requisitos principais, primeiramente, tem-se que fazer uma distinção entre os motoristas que trabalham de forma eventual, como passatempo, e aqueles que utilizam a plataforma como forma de complementação de renda, uma espécie de segundo trabalho, e aqueles que tem o aplicativo como seu único trabalho, cujo ganho mensal decorre, exclusivamente, da atividade de motorista de aplicativo. Essa diferenciação é importante, pois as condições impostas pelos aplicativos possuem impactos diferentes para cada categoria de motoristas (ROSENBLAT, 2018).

Para Rosenblat (2018), os motoristas que trabalham em aplicativos como forma de passatempo, realizam um trabalho mais leve em comparação aos outros, e tem menos razões para exigir melhores condições de trabalho e reconhecimento de direitos trabalhistas, ainda que inseridos no mesmo ramo de atividade. Já os motoristas que utilizam a plataforma como sua principal fonte de rendimento, em decorrência da necessidade, trabalham por jornadas mais extensas e de forma mais constante. No Brasil, estudos apontam que a maioria dos motoristas de Uber tem o aplicativo como fonte principal de renda. Em uma pesquisa realizada por Carelli (2017) verificou-se que dos 40 entrevistados, apenas 15 trabalham no aplicativo como forma de complementação de renda.

No que diz respeito ao requisito da habitualidade, essa é facilmente verificável nos motoristas que possuem o trabalho em aplicativos como sua principal, ou única, fonte de renda. A legislação brasileira não define um prazo mínimo para que o trabalho seja considerado eventual, mas entende-se, doutrinariamente, que o trabalho eventual é aquele que há a "execução de um serviço de curta duração, caracterizado por um predeterminado que as partes estipulam, e com desenvolvimento da atividade, se houver o retorno do eventual, em um parâmetro de intermitência acentuado" (NASCIMENTO, 2011, p. 575). Ainda, entende-se que essa diferenciação entre trabalho eventual e habitual é o que diferencia o empregado do trabalhador autônomo.

\footnotetext{
4 "Art. $3^{\text {o }}$ - Considera-se empregado toda pessoa física que prestar serviços de natureza não eventual a empregador, sob a dependência deste e mediante salário.” (BRASIL, 1943)
} 
Em uma pesquisa realizada por André, Silva e Nascimento (2019), onde foram realizadas entrevistas com onze motoristas da Uber, na cidade do Rio de Janeiro, entre os anos de 2016 e 2017, constatou-se que a maioria dos entrevistados laboravam com habitualidade durante a semana e que perfaziam jornada, muitas vezes, superiores as 8 horas diárias. Assim concluiu a pesquisa:

Os motoristas entrevistados, com exceção de dois, mencionaram que
trabalham regularmente uma carga horária muito maior do que as 8 horas
diárias consideradas normais pela CLT. O motorista 5 menciona que chega
a trabalhar 20 horas por dia e motorista 7 afirma não ter sequer um dia de
descanso apesar de trabalhar de 10 a 12 horas por dia. Um dos motoristas
relatou que a média do trabalho dos motoristas é de 10 a 16 horas diárias.
Os motoristas que não trabalham acima de 8 horas diárias regularmente
admitiram trabalhar mais horas algumas vezes, além de um deles mencionar
que trabalha 7 dias da semana. Cabe destacar, entretanto, que esses
motoristas que têm uma jornada de até 8 horas possuem uma outra fonte
de renda, decorrente de um trabalho regular além do trabalho de motorista [...]
(ANDRÉ; SILVA; NASCIMENTO, 2019, p. 22).

A partir disso, apesar dos aplicativos afirmarem que os motoristas possuem liberdade para definir as próprias jornadas e trabalharem apenas quando quiserem, nota-se que, na realidade, muitos motoristas trabalham todos os dias e com jornada de oito horas ou superior. Isso demonstra que o trabalho em aplicativo, ainda que tenha uma dinâmica de funcionamento diferente das formas já conhecidas de emprego, não há divergência quanto a frequência do serviço prestado, não podendo, portanto, ser considerado apenas um trabalho autônomo.

Já no que diz respeito à subordinação, esta constituí a principal diferença entre o trabalho autônomo e o emprego, e é o ponto onde se verifica a maior modificação trazida pelo trabalho de aplicativo. Conceituando, brevemente, a subordinação, em seu modelo clássico, pode ser entendida como "pôr à disposição a própria força de trabalho a favor da outra parte contratante, endereçada segundo o próprio escopo pessoal do trabalhador, o que se identificou com o submetimento da prestação ao critério diretivo do empregador" (NASCIMENTO, 2011, p. 213). Assim, o empregado fica adstrito ao poder diretivo do empregador, devendo seguir as regras e ordens por este estabelecidas.

O que ocorre no caso do trabalho por aplicativos é uma modificação neste conceito de subordinação, uma vez que, em uma análise superficial da realidade laboral, os motoristas respondem ao poder diretivo do aplicativo. Contudo, como já referido anteriormente, o algoritmo direciona o trabalhador a objetivos determinados pelo aplicativo, 
fazendo com que obedeça a regras e comandos pré-estabelecidos pelo programador (MUCELIN, RIEMENSCHNEIDER, 2019, p. 73).

Assim, há uma modificação no que se entende por poder diretivo, bem como há o tolhimento da autonomia do trabalhador pelo algoritmo. Segundo Carelli (2017, p. 141), "neste ponto encontramos uma contradição própria do novo modelo: ao mesmo tempo em que acena para a entrega de parcela de autonomia ao trabalhador, essa liberdade é impedida pela programação, pela só e mera existência do algoritmo".

O algoritmo da Uber realiza esse controle por meio da precificação unilateral, da distribuição de tarifas dinâmicas, pelo cálculo da média de avaliações do motorista parceiro e do desligamento automático do trabalhador. Dessa forma estabelece-se um novo modelo de subordinação, não mais atrelado ao comando direto do empregador, mas onde a gestão é feita pelo controle algorítmico do trabalho. Conforme afirma Rosenblat (2018, tradução nossa), “o rastreamento quantitativo dá a impressão de que o comportamento do motorista está sendo monitorado dentro do seu próprio carro, ainda que não haja um gerente humano o observando sobre o ombro". ${ }^{5}$

Diante disso, contata-se que o modelo de trabalho uberizado modifica a lógica do trabalho até então conhecida. Os conceitos utilizados para a diferenciação de um trabalho autônomo de uma relação formal de emprego não podem mais ser utilizados quando se falar em trabalho por aplicativo, uma vez que esta nova modalidade deve ser analisada pela lógica algorítmica. Para Bridi e Lima (2019, p. 336),

\footnotetext{
As tecnologias de informação e comunicação (TICs), de fato, não apenas permitiram novos negócios e uma diversidade de arranjos de empresas, como também alteraram o trabalho, as condições de realização do trabalho, as jornadas, os espaços onde o trabalho pode ser realizado, assim como a própria noção de trabalho.
}

Assim, é imprescindível debater quais as modificações derivadas do trabalho uberizado, tanto no âmbito da legislação trabalhista, quanto no entendimento jurisprudencial acerca do reconhecimento de vínculo empregatício entre plataforma e trabalhador-parceiro.

\section{CONSTRUÇÃO DE UM MODELO NORMATIVO PARA O TRABALHO UBERIZADO: A INTERPRETAÇÃO DO TRIBUNAL SUPERIOR DO TRABALHO E AS PROPOSTAS LEGISLATIVAS DE REGULAMENTAÇÃO NO BRASIL}

\footnotetext{
${ }^{5}$ Texto original: "Quantitative tracking gives off the impression that driver behavior is being monitored within the driver's own car, even if a human manager isn't looking over the driver's shoulder."
} 
Diante das modificações trazidas pelo trabalho uberizado no próprio entendimento do que constituí uma relação de emprego, levanta-se o debate acerca da necessidade de regulamentação jurídica do trabalho de aplicativo e, se essa nova dinâmica constitui uma relação trabalhista.

Primeiramente, importante destacar que por ser uma discussão recente, não há ainda, no Brasil, uma legislação própria ou um entendimento jurisprudencial consolidado acerca do assunto. Atualmente, apenas um recurso de revista sobre o vínculo empregatício entre motorista e Uber foi analisado pelo Tribunal Superior do Trabalho, corte máxima em matéria trabalhista. Acerca dos projetos legislativos, analisar-se-á os projetos de lei no 3748/2020 e $6015 / 2019$, os quais visam regulamentar o trabalho em demanda. Tanto o posicionamento do TST quanto os projetos de lei visam solucionar a controvérsia sobre o trabalho sob demanda.

No que diz respeito ao entendimento jurisprudencial brasileiro acerca do trabalho uberizado, o Tribunal Superior do Trabalho (TST) ${ }^{6}$ entende pela inexistência do vínculo empregatício entre motorista e aplicativo - no caso, Uber - utilizando como premissa central a existência de autonomia do motorista, considerando o contrato estabelecido pelas partes um contrato de natureza cível. No voto proferido, no julgamento do Recurso de Revista $n^{\circ}$ 1000123-89.2017.5.02.0038 pela $5^{\circ}$ Turma do TST, o ministro relator afirma que a possibilidade de ficar offline no aplicativo demonstra autonomia por parte do motorista:

\begin{abstract}
Com efeito, o reclamante admite expressamente a possibilidade de ficar "off line", sem delimitação de tempo, circunstância que indica a ausência completa e voluntária da prestação dos serviços em exame, que só ocorre em ambiente virtual.

Tal fato traduz, na prática, a ampla flexibilidade do autor em determinar sua rotina, seus horários de trabalho, locais que deseja atuar e quantidade de clientes que pretende atender por dia. Tal auto-determinação é incompatível com o reconhecimento da relação de emprego, que tem como pressuposto básico a subordinação, elemento no qual se funda a distinção com o trabalho autônomo. (BRASIL, 2020a).
\end{abstract}

Ainda, o acórdão refere que as avaliações dos motoristas realizadas pelos usuários não caracterizam subordinação, uma vez que é uma ferramenta de feedback e de controle de

\footnotetext{
${ }^{6}$ A pesquisa jurisprudencial foi realizada utilizando os termos "motorista uber" e "vínculo empregatício" no repositório autorizado do Tribunal Superior do Trabalho, delimitando a pesquisa no período após a reforma trabalhista (novembro de 2017) até o mês de realização da pesquisa (dezembro de 2020). Dos onze resultados apresentados pela plataforma, foram filtrados apenas aqueles que tiveram o recurso de revista admitido com análise de mérito. Foram excluídos os resultados de embargos de declaração e os recursos não analisados pelo óbice da Súmula 126 do TST, ou seja, que impede a reanálise de provas pelo TST. Assim, considerando os critérios descritos, restou apenas o recurso de revista analisado na presente pesquisa.
} 
qualidade quanto a prestação de serviços. Por fim, o ministro relator afirma que "as relações de trabalho têm sofrido intensas modificações com a revolução tecnológica, de modo que incumbe a esta Justiça Especializada permanecer atenta à preservação dos princípios que norteiam a relação de emprego, desde que presentes todos os seus elementos." (BRASIL, 2020a).

Observa-se que a interpretação da $5^{\circ}$ Turma do TST quanto os elementos constitutivos do trabalho em aplicativo divergem do posicionamento doutrinário estudado no tópico anterior. O acórdão não considera as modificações ocasionadas pelo trabalho uberizado nos próprios requisitos da relação de emprego, mantendo o entendimento da subordinação jurídica clássica e não avalia a possibilidade e existência da subordinação algorítmica. Nesse sentido, analisam Terragno e Nascimento (2020, p. 337):

\begin{abstract}
Consequentemente, o atual contexto trabalhista, social e econômico atual é diferente daquele que originou a Consolidação das Leis do Trabalho, no ano de 1943, devido a diversos fatores como a evolução tecnológica, por exemplo, que proporcionou modos de trabalho que utilizam como principal instrumento a internet, e que passaram a ter cada vez mais relevância no mundo laboral. Contudo, mesmo com mudanças evidentes no Direito do Trabalho, observa-se certa insistência em utilizar e manter as interpretações jurídicas do contexto em que as leis trabalhistas brasileiras foram pensadas.
\end{abstract}

Conforme analisado ao longo desta pesquisa, não se pode observar o modelo de trabalho introduzido pela Economia do Compartilhamento e consolidado pela Uber do mesmo ponto de vista das relações clássicas de trabalho, uma vez que os instrumentos utilizados para a sua execução sequer existiam - tal como smartphones e aplicativos - e, portanto, faz-se necessária uma interpretação extensiva da legislação trabalhista.

Contribui destacar que a Consolidação das Leis do Trabalho possuí instrumentos para lidar com essa nova modalidade de trabalho, uma vez que não há delimitação expressa nos artigos $2^{\circ}$ e $3^{\circ}$ do que consiste na subordinação e o poder diretivo, bem como que o artigo $6^{07}$ remonta a possibilidade de utilização de meios telemáticos e informatizados para controle e supervisão do trabalho, tratando-se, exclusivamente, de um debate interpretativo da realidade fática do trabalho uberizado.

\footnotetext{
7 "Art. $6^{-}$Não se distingue entre o trabalho realizado no estabelecimento do empregador, o executado no domicílio do empregado e o realizado a distância, desde que estejam caracterizados os pressupostos da relação de emprego.

Parágrafo único. Os meios telemáticos e informatizados de comando, controle e supervisão se equiparam, para fins de subordinação jurídica, aos meios pessoais e diretos de comando, controle e supervisão do trabalho alheio" (BRASIL, 1943).
} 
Distintivamente ao entendimento do TST, cumpre analisar, de modo comparativo, o posicionamento adotado pelo Estado da Califórnia, nos Estados Unidos, berço do trabalho uberizado, o qual teve decisão proferida por sua Suprema Corte onde reconheceu a existência de vínculo empregatício entre aplicativo e, neste caso, entregador. O caso Dynamex Operations West. Inc vs Superior Court of Los Angeles resultou na modificação da legislação trabalhista do Estado da Califórnia, estabelecendo critérios para a classificação dos trabalhadores dos aplicativos de Economia Compartilhada.

Como consequência direta do julgamento, aprovou-se a Assembly Bill 5, ou AB5, a qual estabelece uma espécie de teste - teste $\mathrm{ABC}$ - sob qual as empresas-aplicativos poderão ser submetidas, que determinará se os trabalhadores são independentes ou empregados. O teste consiste na avaliação dos seguintes critérios:

\footnotetext{
O trabalhador está livre do controle e direção da entidade contratante com relação à performance do trabalho, tanto sobre o contrato de trabalho, quanto no desempenho do trabalho;

O trabalhador realiza o trabalho fora do curso normal dos negócios da entidade contratante, e;

O trabalhado está habitualmente engajado em um comércio, ocupação ou negócio estabelecido independentemente, da mesma natureza envolvida no trabalho realizado. (STATE OF CALIFORNIA, 2019, tradução nossa) ${ }^{8}$.
}

No caso de a empresa-aplicativo respeitar os três critérios acima descritos, o trabalhador será reconhecido como independente e será afastado o vínculo empregatício. Este afastamento não é automático, devendo ser averiguado por meio de ação própria.

Entretanto, o julgamento do caso Dynamex e a aprovação do AB5 abre precedente para discussão do enquadramento de milhares de trabalhadores de aplicativos de Economia Compartilhada. Atentando para essas modificações, o Procurador-geral da Califórnia, em conjunto com um grupo de advogados, ajuizaram ação contra a Uber por violação da legislação estadual (CONGER, 2020).

No caso brasileiro, buscando a regulamentação do trabalho sob demanda, ou trabalho uberizado, foi proposto, em julho de 2020, o projeto de lei (PL) $n^{\circ} 3748 / 2020$, pela Deputada

\footnotetext{
${ }^{8}$ Texto original: "The worker is free from the control and direction of the hiring entity in connection with the performance of the work, both under the contract for the performance of the work and in fact; The worker performs work that is outside the usual course of the hiring entity's business; and The worker is customarily engaged in an independently established trade, occupation, or business of the same nature as that involved in the work performed"
} 
Tabata Amaral, o qual busca regulamentar o trabalho sob demanda. O PL considera trabalho sob demanda todo aquele "em que os clientes contratam a prestação de serviços diretamente com a plataforma de serviços sob demanda, que, por sua vez, apresenta proposta para execução dos serviços para um ou mais trabalhadores” (BRASIL, 2020b).

Diferentemente da solução adotada pela Califórnia, o PL estabelece um modelo de regulamentação própria do trabalho sob demanda, excluindo, para estes fins, a aplicação da $\mathrm{CLT}^{9}$. O PL também dispõe, no artigo $2^{\circ}$, parágrafo $4^{\circ}$, que, ainda que o trabalhador esteja submetido aos termos desta lei, não impede a caracterização de vínculo empregatício entre o trabalhador e um determinado cliente (BRASIL, 2020b). O projeto de lei traz a possibilidade de aplicação da CLT apenas nos casos em que esteja descaracterizada a liberdade do trabalhador para a prestação do serviço, como impossibilidade de cadastro em outros aplicativos, definição de tempo mínimo para execução do serviço, limitação de intervalo.

Nota-se, portanto, que o texto limita a possibilidade de discussão de existência de vínculo empregatício entre trabalhador e aplicativo, criando uma nova modalidade de trabalho exclusiva para o trabalho sob demanda, com características similares ao trabalho autônomo, porém considerando as peculiaridades das plataformas.

Entretanto, isso não significa a exclusão de todo e qualquer direito trabalhista. No artigo $5^{\circ}$ ficam estabelecidos os critérios de remuneração do trabalho sob demanda, observando, inclusive, os direitos constitucionais assegurados aos trabalhadores, tais como salário correspondente ao piso da categoria, férias com o adicional constitucional de 1/3 (um terço), e $13^{\circ}$ salário:

\footnotetext{
Art. $5^{\circ} \mathrm{O}$ trabalhador sob demanda poderá ser remunerado por meio de verba única, devendo seu valor, contudo, ser suficiente para assegurar um salário-hora de trabalho nunca inferior ao salário profissional-hora ou ao piso da categoria por hora, ou, quando estes forem inexistentes, ao salário mínimo-hora, em qualquer das hipóteses acrescido de:

I - 1/12 (um doze avos), correspondendo ao $13^{\circ}$ salário proporcional;

II - 1/12 (um doze avos), correspondendo às férias proporcionais; $\mathrm{e}$

III - 1/36 (um trinta e seis avos), correspondendo ao 1/3 (um terço) constitucional de adicional e férias.

$\S 1^{\circ}$ Para fins de cálculo do salário-hora de trabalho será considerado o tempo efetivo de prestação dos serviços acrescido de $30 \%$ (trinta por cento), a título de tempo de espera. (BRASIL, 2020b)
}

\footnotetext{
9 “Art. $1^{\circ}$ É instituído o regime de trabalho sob demanda, nas condições estabelecidas na presente Lei. Parágrafo único. Aos trabalhadores em regime de trabalho sob demanda não se aplicam as disposições da Consolidação das Leis do Trabalho (CLT), aprovada pelo Decreto-Lei $n^{\circ} 5.452$, de $1^{\circ}$ de maio de 1943." (BRASIL, 2020b).
} 
Prevê também, uma série de proteções sociais, tal como o direito ao percebimento do seguro-desemprego ao trabalhador em regime de trabalho sob demanda que tiver laborado por pelo menos quinze meses nos últimos vinte e quatro meses que antecedem à data do descadastramento, a filiação ao regime geral de previdência social na qualidade de segurado empregado, o direito ao auxílio-doença, assistência nos casos de acidente de trabalho, licença e salário-maternidade e salário-família (BRASIL, 2020b).

Além disso, o projeto de lei também dispõe sobre a necessidade de indenização pelos custos com insumos, manutenção e depreciação dos instrumentos próprios do trabalhador utilizados para a execução do serviço, bem como estabelece critérios as políticas de descadastramento, como necessidade de clareza e publicidade, possibilidade de revisão das decisões, ainda que tomadas exclusivamente por algoritmo e acesso aos dados mantidos pela plataforma.

Por último, o projeto de lei define a competência da Justiça do Trabalho para processar e julgar demandas entre trabalhadores e aplicativos do regime de trabalho sob demanda. Tal situação difere do atual posicionamento do Superior Tribunal de Justiça, o qual definiu, no julgamento do Conflito de Competência $n^{\circ} 164.544$ - MG, a competência da Justiça Comum para julgar causas derivadas da Economia Compartilhada, afirmando que o contrato estabelecido entre aplicativo e trabalhador é de cunho eminentemente cível (BRASIL, 2019a).

Acerca do projeto de lei $\mathrm{n}^{\circ}$ 6015/2019, de autoria de Mário Heringer, este tem como proposta a criação de nova seção na CLT exclusiva para os empregados por empresa gestora de plataforma digital ou informatizada. Diferentemente do projeto de lei anteriormente analisado, este considera os trabalhadores de aplicativos como empregados, obedecendo as disposições da CLT sobre o contrato de trabalho, tal como fixação de jornada, remuneração, inclusive as normas sobre rescisão contratual (BRASIL, 2019b).

A partir disso, verifica-se que ainda não há um consenso sobre o enquadramento do trabalhador de aplicativo. Enquanto o TST adota o posicionamento de que o contrato estabelecido entre trabalhador e aplicativo é de natureza cível, o legislativo busca criar um novo modelo normativo para o trabalho uberizado.

\section{CONCLUSÃO}


A Economia do Compartilhamento, ainda que não se trate de um modelo de negócio tão recente, contribuiu nas últimas décadas para a formação de uma organização de trabalho completamente nova. A utilização dos smartphones e aplicativos como meio para a prestação de serviços apresentou-se, primeiramente, como uma alternativa ao desemprego e instabilidade financeira.

Com a sua expansão e popularização, essa nova modalidade de trabalho deixou de ser apenas um trabalho secundário e passou a ser a principal fonte de renda de muitos trabalhadores, o que teve por consequência a reestruturação das dinâmicas do trabalho. Essa nova classe de trabalhadores uberizados, seguem, ainda, sem qualquer regulamentação jurídica própria, como é o caso brasileiro.

As peculiaridades do trabalho uberizado fazem com que a aplicação das normas trabalhistas já existentes seja mais difícil, uma vez que ao mesmo passo em que possuí superficialmente as características de um trabalho autônomo, se adotado um olhar mais crítico sobre o controle exercido pelo algoritmo do aplicativo, também se verifica a existência dos requisitos para a configuração de uma relação de emprego.

Essa controvérsia ainda não chegou a sua conclusão. Como visto, não há um posicionamento homogêneo entre o judiciário e o legislativo sobre como deve ser regulamentado o trabalho uberizado. Entretanto, a criação de um modelo normativo torna-se cada vez mais necessário, considerando o crescimento desta classe de trabalhadores no Brasil.

Portanto, em resposta ao problema de pesquisa levantado, tem-se que a Economia do Compartilhamento, principalmente os aplicativos de prestação de serviços como o Uber, alteraram consideravelmente as dinâmicas de trabalho a partir da inserção da tecnologia da informação e comunicação como meio indispensável para a execução do trabalho. Dessa forma, torna-se necessário uma modificação interpretativa dos conceitos que permeiam as relações de emprego e, alternativamente, a construção de um modelo normativo, a fim de que sejam garantidas as proteções trabalhistas e sociais a esses trabalhadores.

\section{REFERÊNCIAS}

ABILIO, Ludmila Costhek. Uberização: do empreendedorismo para o autogerenciamento subordinado. In: Psicoperspectivas, vol.18, nº. 3. 2019. 
ANDRÉ, Robson Gomes; SILVA, Rosana Oliveira da; NASCIMENTO, Rejane Prevot.

"Precário não é, mas eu acho que é escravo": Análise do Trabalho dos Motoristas da Uber sob o Enfoque da Precarização. In: Revista Eletrônica de Ciência Administrativa. v.18 n.1 p.734 jan-mar 2019. Curitiba. 2019. Disponível em:

http://www.periodicosibepes.org.br/index.php/recadm/article/view/2544. Acesso em: 25 dez. 2020.

ANTUNES, Ricardo; FILGUEIRAS, Vitor. Plataformas digitais, Uberização do trabalho e regulação no Capitalismo contemporâneo. In: Contracampo, Niterói, v. 39, n. 1, p. 27-43, abr./jul. 2020.

BRASIL. Decreto-Lei $n^{0}$ 5.452, de $1^{0}$ de maio de 1943: Consolidação das Leis do Trabalho. Disponível em: http://www.planalto.gov.br/ccivil_03/decreto-lei/del5452.htm. Acesso em: 23 dez. 2020.

BRASIL. Câmara dos Deputados. Projeto de Lei no 3748/2020. Institui e dispõe sobre o regime de trabalho sob demanda. 2020. Disponível em:

https://www.camara.leg.br/proposicoesWeb/fichadetramitacao?idProposicao=2257468. Acesso em: 28 dez. 2020.

BRASIL. Câmara dos Deputados. Projeto de Lei no 6015/2019. Altera o Decreto-Lei $n^{\circ}$ 5.452, de $1^{\circ}$ de maio de 1943, a Consolidação das Leis do Trabalho (CLT), para incluir entre as Disposições Especiais sobre duração e condições de trabalho a Seção XIII-A, dos "Empregados em Serviços Contratados e Geridos por Intermédio de Plataformas Digitais", e dispõe sobre a regularização de quadro de funcionários de "trabalho por aplicativo" junto à Justiça do Trabalho. 2019b. Disponível em:

https://www.camara.leg.br/proposicoesWeb/prop_mostrarintegra?codteor=1834812\&filenam e=PL+6015/2019. Acesso em: 29 dez. 2020.

BRASIL. Superior Tribunal de Justiça. Conflito de Competência n ${ }^{\circ} 164.544$ - MG. Relator: Ministro Moura Ribeiro. Publicado em 04 set. 2019. 2019a. Disponível em:

https://processo.stj.jus.br/processo/revista/documento/mediado/?componente=ITA\&sequencia $\mathrm{l}=1857953 \&$ num_registro $=201900799520 \&$ data $=20190904 \&$ formato=PDF. Acesso em: 29 dez. 2020.

BRASIL. Tribunal Superior do Trabalho. Recurso de Revista: 1000123-89.2017.5.02.0038.

Relator: Ministro Breno Medeiros. Julgado em 07 fev. 2020. 2020a. Disponível em: http://aplicacao5.tst.jus.br/consultaDocumento/acordao.do?anoProcInt=2019\&numProcInt=24 2502\&dtaPublicacaoStr=07/02/2020\%2007:00:00\&nia=7443195. Acesso em: 27 dez. 2020.

BRIDI, Maria Aparecida; LIMA, Jacob Carlos. Trabalho digital e emprego: a reforma trabalhista e o aprofundamento da precariedade. In: Caderno CRH. Salvador, v.32, n.86, p.325-341. Maio/Ago.2019. Disponível em:

https://periodicos.ufba.br/index.php/crh/article/view/30561. Acesso em: 27 dez. 2020.

CARELLI, Rodrigo de Lacerda. O Caso Uber e o Controle por Programação: de carona para o século XXI. In: LEME, Ana Carolina Reis Paes; RODRIGUES, Bruno Alves; CHAVES JÚNIOR, José Eduardo de Resende (Coords.). Tecnologias disruptivas e a exploração do 
trabalho humano: a intermediação de mão de obra a partir das plataformas eletrônicas e seus efeitos jurídicos e sociais. São Paulo: LTr, 2017.

CONGER, Kate. California Sues Uber and Lyft, Claiming Workers Are Misclassified. The New York Times. 05 maio 2020. Disponível em:

https://www.nytimes.com/2020/05/05/technology/california-uber-lyft-lawsuit.html. Acesso em: 28 dez. 2020.

FERRAZ, Deise Luiza da Silva; FRANCO, David Silva. Uberização do trabalho e acumulação capitalista. In: Cadernos EBAPE.BR, v. 17, Edição Especial, Rio de Janeiro. Nov. 2019. p. 844-856.

FONTES, Virginia. Capitalismo em tempos de uberização: do emprego ao trabalho. In: Marx e Marxismo. Publicação do Núcleo Interdisciplinarde Estudos sobre Marx e Marxismo, UFF, Niterói,v.5, n.8, jan/jun.p.45-67, 2017. Disponível em:

http://www.niepmarx.blog.br/revistadoniep/index.php/MM/article/view/220/177. Acesso em: 23 dez. 2020.

HARARI, Yuval Noah. Homo Deu: uma breve história do amanhã. São Paulo: Companhia das Letras, 2016.

KRAMER, Josiane Caldas. A economia compartilhada e a uberização do trabalho: utopias do nosso tempo? Orientadora: Dra. Liana Maria da Frota Carleial. 2017. 129 f. Dissertação (Mestrado) - Curso de Pós-Graduação em Direito, Universidade Federal do Paraná, Curitiba, 2017. Disponível em: https://www.acervodigital.ufpr.br/handle/1884/47786. Acesso em: 23 dez. 2020.

MUCELIN, Guilherme Antônio Balczarek; RIEMENSCHNEIDER, Patrícia Strauss. Economia do compartilhamento: a lógica algorítmica das plataformas virtuais e a necessidade de proteção da pessoa nas atuais relações de trabalho. In: Revista Eletrônica Direito e Sociedade. v.7, n.1, Canoas, 2019. p. 61-93.

NASCIMENTO, Amauri Mascaro. Curso de Direito do Trabalho. 26 a ed. São Paulo: Saraiva, 2011.

NASCIMENTO, Andrele; TERRAGNO, Pedro Custódio. Uberização e precarização do trabalho: a nova relação de emprego e as consequências do não reconhecimento de vínculo empregatício pelos tribunais. In: Res Severa Verum Gaudium. v.5, n.1. 2020. p. 321-343. Disponível em: https://www.seer.ufrgs.br/resseveraverumgaudium/article/view/104637. Acesso em: 27 dez. 2020.

ROSENBLAT, Alex. Uberland: how algorithms are rewriting the rules of work. Oakland, California: University of California Press. 2018.

SCHOR, Juliet. Debatendo a economia do compartilhamento In: Economias do compartilhamento e o direito. Org. Rafael A.F. Zanatta, Pedro C.B de Paula, Beatriz Kira. Curitiba: Juruá, 2017. p. 21-40.

SLEE, Tom. Uberização: a nova onda do trabalho precarizado. São Paulo: Elefante. 2017. 
STATE OF CALIFORNIA (EUA). Department of Industrial Relations. Independent contractor versus employee. 2019. Disponível em:

https://www.dir.ca.gov/dlse/faq_independentcontractor.htm. Acesso em: 28 dez. 2020.

UBER. Dirija. 2020a. Disponível em: https://www.uber.com/br/pt-br/drive/. Acesso em: 23 dez. 2020.

UBER. Aviso de privacidade da Uber. 2020b. Disponível em:

https://www.uber.com/legal/pt-br/document/?name=privacy-notice\&country=brazil\&lang=ptbr. Acesso em: 23 dez. 2020.

UBER. Fatos e Dados sobre a Uber. 2020d. Disponível em: https://www.uber.com/ptBR/newsroom/fatos-e-dados-sobre-uber/. Acesso em: 23 dez. 2020.

UBER. Termos e Condições do Programa Uber Pro. 2020c. Disponível em: https://www.uber.com/legal/pt-br/document/?name=uber-pro-programterms\&country=brazil\&lang=pt-br. Acesso em 24 dez. 2020.

ZANATTA, Rafael A. F. Economias do Compartilhamento: superando um problema conceitual. In: Economias do compartilhamento e o direito. Org. Rafael A.F. Zanatta, Pedro C.B de Paula, Beatriz Kira. Curitiba: Juruá, 2017. p. 79-106. 